\title{
PENGARUH PDB, JUMLAH PENDUDUK DAN INDEKS PEMBANGUNAN MANUSIA TERHADAP KEMISKINAN PADA KAB/KOTA DI PROVINSI ACEH
}

\author{
Jannatun Nufus ${ }^{1}$, Ratna Husein ${ }^{2}$, \\ ${ }^{a}$ Fakultas Ekonomi dan Bisnis Universitas Malikussaleh \\ 1Corresponding author: ratna@unimal.ac.id \\ 2 jannatunnufus1@gmail.com
}

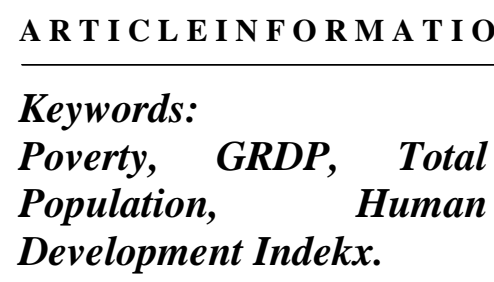

A B S T R A C T

This study aims to determine the effects of GRDP, population, and HDI on poverty in 23 districts/cities in Aceh Province. This study uses secondary data obtained from the Central Bureau of Statistics during 2012-2018 and cross-section data from 23 districts/cities, thus forming a total panel data of 161 data. The data analysis method used is a panel data regression model using the Eviews 9 program. The results show that partially the GRDP and population do not have a significant and negative effect on poverty in districts/cities in Aceh Province. Meanwhile, HDI partially has a significant and negative effect on the poverty of districts/cities in Aceh Province. The magnitude of the influence of GRDP, total population, and HDI on poverty is 0.374 (37.4\%), while those influenced by other variables outside this model are 0.626 (62.6\%). Suggested: Local governments should increase subsector efforts to boost GDP, to reduce poverty levels.

\section{PENDAHULUAN}

Kemiskinan merupakan masalah global yang menjadi tantangan yang harus dihadapi dan dicarikakan solusi bagi suatu negara. Kemiskinan yang menjadi sorotan dalam penelitian ini adalah jumlah penduduk miskin di Provinsi Aceh. Provinsi Aceh terdiri dari 23 Kabupaten/Kota. Dalam beberapa aspek terdapat berbagai perbedaan karakteristik antara Kabupaten maupun kota. Perbedaan tersebut dapat berpengaruh terhadap banyaknya jumlah penduduk miskin.

Wongdesmiwati, (2009) menyatakan bahwa kemiskinan dapat dipengaruhi oleh tingkat pertumbuhan produk domestik regional bruto (PDRB) riil dan faktor-faktor pendukung lainnya, seperti investasi melalui penyerapan tenaga kerja yang dilakukan baik oleh swasta maupun pemerintah, dengan perkembangan teknologi yang semakin produktif dan inovatif, serta pertumbuhan penduduk melalui IPM.

Membaiknya pertumbuhan ekonomi diharapkan mampu memberikan dampak yang baik bagi permasalahan kemiskinan yang menjadi persoalan penting bagi tiap negara. PDRB adalah salah satu indikator pembangunan. Jika PDB suatu daerah semakin tinggi, maka semakin bagus pula potensi sumber penerimaan daerah. Hal ini karena semakin besarnya pendapatan yang diperoleh oleh masyarakat (Thamrin, 2001). Hasil penelitian senada yang pernah dilakukan bahwa PDRB berpengaruh secara negatif terhadap kemiskinan oleh (Alhudori, 2017), (Hardinandar, 2019) dan (Silastri, 2017).

Selanjutnya, salah satu sumber yang berpengaruh terhadap kemiskinan adalah Indeks Pembangunan Manusia. Indeks Pembangunan Manusia (IPM) merupakan suatu terobosan dalam menilai pembangunan manusia. kualitas manusia yang bertambah baik akan menjadi penunjang faktor berkurangnya penduduk miskin. Jika IPM meningkat maka menunjukkan bahwasannya keadaan hidupsemakin berkualitas sehingga kesejahteraan semakin tinggi dan tingkat kemiskinan akan berkurang (Franciari \& Sugiyanto, 2013) Penelitian serupa juga pernah dilakukan oleh (Syaifullah \& Nazaruddin, 2017) dimana indeks pembangunan manusia berpengaruh secara negatif dan signifikan terhadap kemiskinan. 
Tabel 1

Perkembangan PDRB Migas, Jumlah Penduduk, Indeks Pembangunan Manusia dan Kemiskinan Kab/Kota SeProvinsi Aceh Tahun 2018

\begin{tabular}{|c|c|c|c|c|}
\hline Kab/Kota & $\begin{array}{c}\text { PDRB } \\
\text { (Juta Rp) }\end{array}$ & $\begin{array}{c}\text { JP } \\
\text { (Jiwa) }\end{array}$ & $\begin{array}{r}\text { IPM } \\
(\%) \\
\end{array}$ & $\begin{array}{c}\text { KMK } \\
(\%)\end{array}$ \\
\hline Simeulue & $1.533 .752,9$ & 92.393 & 64.74 & 19,78 \\
\hline Aceh Singkil & $1.664 .659,5$ & 121.681 & 68.02 & 21,25 \\
\hline Aceh Selatan & $4.068 .952,1$ & 235.115 & 65.92 & 14,01 \\
\hline Aceh Tenggara & $3.296 .481,1$ & 212.417 & 68.67 & 14,29 \\
\hline Aceh Timur & $7.815 .855,1$ & 427.567 & 66.82 & 14,49 \\
\hline Aceh Tengah & $5.634 .457,0$ & 208.505 & 72.64 & 15,58 \\
\hline Aceh Barat & $6.586 .297,9$ & 205.971 & 70.47 & 19,31 \\
\hline Aceh Besar & $9.588 .178,2$ & 417.302 & 72.73 & 14,47 \\
\hline Pidie & $7.459 .425,4$ & 439.131 & 69.93 & 20,47 \\
\hline Bireuen & $9.582 .265,5$ & 461.726 & 71.37 & 14,31 \\
\hline Aceh Utara & $16.356 .386,2$ & 611.435 & 68.36 & 18,27 \\
\hline $\begin{array}{l}\text { Aceh Barat } \\
\text { Daya }\end{array}$ & $2.869 .170,9$ & 148.111 & 65.67 & 17,1 \\
\hline Gayo Lues & $1.931 .415,4$ & 92.602 & 65.88 & 20,7 \\
\hline Aceh Tamiang & $5.728 .247,8$ & 29.112 & 68.45 & 14,21 \\
\hline Nagan Raya & $6.119 .935,7$ & 164.483 & 68.15 & 18,97 \\
\hline Aceh Jaya & $1.922 .660,6$ & 91.087 & 68.83 & 14,16 \\
\hline Bener Meriah & $3.476 .900,2$ & 145.086 & 72.14 & 20,13 \\
\hline Pidie Jaya & $2.502 .506,3$ & 158.091 & 72.12 & 20,17 \\
\hline $\begin{array}{l}\text { Kota Banda } \\
\text { Aceh }\end{array}$ & $14.562 .443,8$ & 265.111 & 84.37 & 7,25 \\
\hline Kota Sabang & $1.074 .907,7$ & 34.571 & 74.82 & 16,31 \\
\hline Kota Langsa & $3.701 .610,9$ & 174.318 & 76.34 & 10,79 \\
\hline $\begin{array}{l}\text { Kota } \\
\text { Lhokseumawe }\end{array}$ & $6.837 .195,7$ & 203.284 & 76.62 & 11,81 \\
\hline $\begin{array}{l}\text { Kota } \\
\text { Subulussalam }\end{array}$ & $1.307 .645,9$ & 80.215 & 63.48 & 18,51 \\
\hline Provinsi Aceh & $126.824 .491,4$ & 5.281 .314 & 71.19 & 15.97 \\
\hline
\end{tabular}

Sumber: BPS Aceh, 2019

Tabel di atas menunjukkan nilai PDRB Kab/Kota di Provinsi Aceh tahun 2018, adapun $\mathrm{Kab} /$ Kota dengan PDRB tertingi adalah Kabupaten Aceh Utara yakni sebesar Rp.16.356.386,2, kemudian Kota Banda Aceh Rp.14.562.443,8 dan selanjutnya disusul oleh Kabupaten Aceh Besar sebesar Rp. 9.588.178,2. Sedangkan Kab/Kota dengan nilai PDRB terendah adalah Kota Sabang yaitu sebesar Rp.1.074.907,7, lalu Kota Subulussalam yaitu sebesar Rp.1.307.645,9 dan selanjutnya adalah Simeulue yakni Rp.1.533.752,9.

Kemudian jumlah penduduk pada tahun 2018 dari hasil proyeksi yaitu sebanyak 5.281.314 jiwa. Kabupaten Aceh Utara mempunyai jumlah penduduk tertinggi, yaitu 611,44 ribu jiwa, diikuti oleh Kabupaten Bireuen 461,73 ribu jiwa dan Kabupaten Pidie 439,13 ribu jiwa. Sementara itu, jumlah penduduk paling sedikit terdapat pada Kabupaten Aceh Tamiang yaitu 29.112 jiwa, diikuti oleh Kota Sabang 34.571 jiwa dan Kota Subulussalam 80.215 jiwa.
Kepadatan penduduk Aceh tahun 2018 adalah 91 jiwa per kilometer perseginya. Kepadatan penduduk di perkotaan pada umumnya akan lebih tinggi dibandingkan dengan kepadatan penduduk yang berada di Kabupaten. Kota Banda Aceh mempunyai kepadatan penduduk tertinggi yaitu $4.321 \mathrm{jiwa} / \mathrm{km}^{2}$.Sedangkan kepadatan penduduk terendah adalah di Kabupaten Gayo Lues dengan $16 \mathrm{jiwa} / \mathrm{km}^{2}$ (BPS Provinsi Aceh, 2019).

Selanjutnya IPM, adapun Kab/kota dengan tingkat IPM tertinggi adalah Kota Banda Aceh yakni $84.37 \%$, diikuti oleh Kota Lhokseumawe $76.62 \%$ kemudian Kota Langsa $76.34 \%$. Sementara $\mathrm{Kab} /$ Kota dengan IPM terendah adalah Kota Subulussalam yakni $63.48 \%$, Simeulue $64,74 \%$ dan Kab ABD 65.67\%.

Berdasarkan data tabel 1 pada tahun 2018, jumlah penduuduk miskin tertinggi terdapat pada Kab Aceh Singkil yaitu 21.25\%, diikuti oleh Kab Gayo Lues 20.70\% dan Kab Pidie 20.47\%. Sementara itu jumlah penduduk miskin terendah terdapat pada Kota Banda Aceh yakni 7.25\%, kemudian Kota Langsa $10.79 \%$ serta Kota Lhokseumawe $11.81 \%$.

Jumlah penduduk miskin di Provinsi dalam regional Sumatera masih mengalami pasang surut setiap tahunnya. Sementara itu, pada tahun 2018 Aceh menempati urutan ke 9 sebagai Provinsi dengan persentase penduduk miskin tertinggi di Indonesia. Di Provinsi Aceh, jumlah penduduk miskin pada tahun 2018 mencapai sebanyak 831,50 ribu jiwa atau 15,68 persen dari total penduduknya. Pada tahun 2018 dari hasil proyeksi yaitu sebanyak 5.281.314 jiwa. Laju pertumbuhan penduduk sebesar 1,77 persen dibandingkan data penduduk tahun 2017 (BPS Provinsi Aceh, 2019).

Keberhasilan Provinsi Aceh dalam menanggulangi kemiskinan belum sepenuhnya berhasil. Ini terbukti dengan persentase kemiskinan yang tinggi yakni diatas $15 \%$. Berdasarkan data (BPS Provinsi Aceh, 2019) setelah diolah diketahui bahwa rata-rata tingkat kemiskinan ProvinsiAceh tahun 2014 hingga tahun 2018 masih tinggi yakni di atas $16 \%$. Pemerintah pusat maupun daerah sudah berupaya melaksanakan kebijakan/program demi menanggulangi kemiskinan, tetapi hasilnya masih belum optimal.

Melalui data pada tabel 1 , meskipun angka kemiskinan sudah menurun, jika dilihat dengan tahun-tahun sebelumnya namun tidak menutupi fakta bahwasanya presentase penduduk kurang mampu masih relatif tinggi, artinya pemerintah belum bisa mengatasi permasalahan kemiskinan di Provinsi Aceh. 
Selain itu jika dibandingkan antara $\mathrm{Kab} /$ Kota yang satu dengan Kab/Kota yang lainnya ternyata masih terdapat banyak kesenjangan/ketimpangan. Dimana Kab/Kota yang memiliki jumlah penduduk sedikit, IPM yang rendah serta PDRB yang tidak terlalu tinggi memiliki persentase penduduk miskin yang rendah. Sementara Kab/Kota dengan IPM, PDRB, serta IPM tinggi, yang seharusnya memiliki persentase jumlah penduduk miskin yang rendah justru memiliki persentase penduduk miskin yang banyak.

Kesenjangan yang terjadi di Provinsi Aceh menunjukkan adanya trend penurunan sejak tahun 2011. Hal ini diduga sebagai efek dari adanya pembangunan melalui sejumlah dana perimbangan yang besar, khususnya dana OTSUS. Adapun kekhawatiran yang terjadi dari hasil deskripsi kesenjangan Aceh, terlihat mengalami kenaikan pada periode tahun 2014-2016 ((Andriyani \& Juliansyah, 2018)

Misalnya seperti Kabupaten Aceh Utara pada tahun 2018 memiliki nilai PDRB tertinggi dan jumlah penduduk terbanyak dibandingkan Kab/Kota lainnya, seharusnya berdampak memiliki jumlah penduduk miskin terendah. Namun yang terjadi justru Aceh Utara berada di urutan ke-14 dengan persentase jumlah penduduk miskin terbanyak dari total $23 \mathrm{Kab} /$ Kota yang ada di Provinsi Aceh. Sedangkan untuk Kab Aceh Selatan, Aceh Timur, Aceh Barat Daya yang sudah jelas memiliki nilai PDRB, IPM serta jumlah penduduk lebih sedikit daripada Aceh Utara namun masih memiliki persentase jumlah penduduk miskin yang lebih kecil daripada Aceh Utara.

Penelitian ini bertujuan untuk mengetahui seberapa besar pengaruh PDRB, jumlah penduduk dan IPM terhadap kemiskinan pada Kab/Kota di Provinsi Aceh. Selanjutnya pembahasan di bagian kedua dalam artikel ini adalah kajian teori, dibagian ketiga dibahas tentang metode penelitian. Pada bagian keempat membahas hasil dan pembahasan dan akhirnya tutup dengan kesimpulan dan saran pada bagian kelima.

\section{KAJIAN TEORITIS}

\section{Kemiskinan}

Suparlan (2004) menjelaskan kemiskinan merupakan suatu keadaan dengan standar hidup yang rendah, yakni adanya suatu tingkat kekurangan pada sekelompok orang yang berdampak terhadap tingkat kesehatan, rasa harga diri serta kehidupan moral masyarakat yang dikategorikan sebagai penduduk miskin.

Kemiskinan ada saat manusia itu tidak dapat memenuhi segala kebutuhan minimalnya. Kebutuhan minimal yakni kebutuhan akan pangan, sandang dan kebutuhan sosial lainnya yang diperlukan oleh penduduk agar dapat hidup dengan layak (Ritonga, 2003), Di Indonesia, kesejahteraan umum bisa digambarkan melalui tingkat kemiskinan penduduk. Ada hubungan yang negatif antara kesejahteraan umum dan tingkat kemiskinan. Jika kesejahteraan penduduk tinggi, maka tingkat kemiskinan akan rendah. (Arsyad, 2004) mengemukakan bahwasannya kemiskinan yaitu kelaparan, mengalami ketakutan dalam umum di Indonesia dapat digambarkan salah satunya berdasarkan tingkat kemiskinan

menghadapi masa depan, tidak mempunyai pekerjaan, ketidakberdayaan, hilang anak karena penyebab sakit, terasingkan serta tidak memiliki rasa bebas.

Dari penjelasan diatas dapat disimpulkan bahwasannya kemiskinan yaitu salah satu dari sekian banyaknya permasalahan ekonomi, dimana keadaan seseorang tidak dapat memenuhi segala kebutuhan diantaranya kesehatan, hidup yang berkecukupan, harga diri, serta rasa dihormati.

\section{PDRB}

Salah satu indikator penting untuk mengetahui kondisi ekonomi di suatu daerah dalam suatu periode tertentu adalah data Produk Domestik Regional Bruto (PDRB), baik atas dasar harga berlaku maupun atas dasar harga konstan. PDRB pada dasarnya merupakan jumlah nilai tambah (value added) yang dihasilkan oleh seluruh unit usaha dalam suatu daerah tertentu, atau merupakan jumlah nilai barang dan jasa akhir (neto) yang dihasilkan oleh seluruh unit ekonomi (Widodo, 2009).

Berdasarkan beberapa uraian di atas maka dapat disimpulkan bahwasannya PDRB adalah data statistik yang merangkum perolehan nilai tambah dari seluruh kegiatan ekonomi pada satu periode tertentu. PDRB dihitung dalam dua cara, yaitu atas dasar harga berlaku dan atas dasar harga konstan.

\section{Jumlah Penduduk}

Penduduk merupakan setiap manusia yang menetap diwilayah geografis negara Indonesia dalam waktu 6 bulan atau lebih dan atau mereka yang tinggal kurang dari 6 bulan tetapi bertujuan untuk menetap (BPS Provinsi Aceh, 2019). Penduduk merupakan unsur penting dalam kegiatan ekonomi serta usaha membangun suatu 
perekonomian karena penduduk menyediakan tenaga kerja, tenaga ahli, pimpinan perusahaan tenaga kerja usahawan dalam menciptakan kegiatan ekonomi (Sukirno, 2005).

Berdasarkan uraian di atas maka dapat disimpulkan bahwasannya penduduk adalah kumpulan manusia yang menempati wilayah tertentu yang dapat berubah sewaktu-waktu karena adanya proses kelahiran, kematian dan perpindahan dari satu wilayah ke wilayah yang lain.

\section{Indeks Pembangunn Manusia}

IPM adalah salah satu alat ukur yang dapat digunakan untuk menilai kualitas pembangunan manusia, baik dari sisi dampaknya terhadap kondisi fisik manusia (kesehatan dan kesejahteraan) maupun yang bersifat non-fisik (intelektualitas) (BPS, 2019).Indek pembangunan manusia adalah suatu gambaran yang dilihat dari sisi perluasan, pemerataan, dan keadilan baik dalam keselamatan, pendidikan, maupun kesejahteraan masyarakat (Todaro, 2006).

IPM merupakan pengukuran perbandingan harapan hidup, melek huruf, pendidikan dan standar hidup untuk semua negara di seluruh dunia.bahwa IPM merupakan suatu indikator untuk mengukur keberhasilan suatu pembangunan yang diharapkan yang dilakukan suatu tempat atau daerah. Dengan beberapa komponen antaralain daya beli masyarakat angka harap hidup, serta angka melek huruf (Davies, 2018).

\section{Kerangka Konseptual}

Hasil penelitian senada yang pernah dilakukan bahwa PDRB berpengaruh secara negatif terhadap kemiskinan oleh Alduhori (2017), Hardinandar (2019) dan Silastri (2017). Berdasarkan penelitian Herman (2018) menunjukkan bahwa jumlah penduduk berpengaruh secara signifikan terhadap kemiskinan. Selanjutnya, penelitian serupa juga pernah dilakukan oleh Syaifullah (2017), dimana indeks pembangunan manusia berpengaruh secara negatif dan signifikan terhadap kemiskinan.

Berdasarkan landasan teoritis yang telah dikemukan di atas maka dapat disimpulkan bahwasannya kerangka konseptual pada gambar di bawah ini:

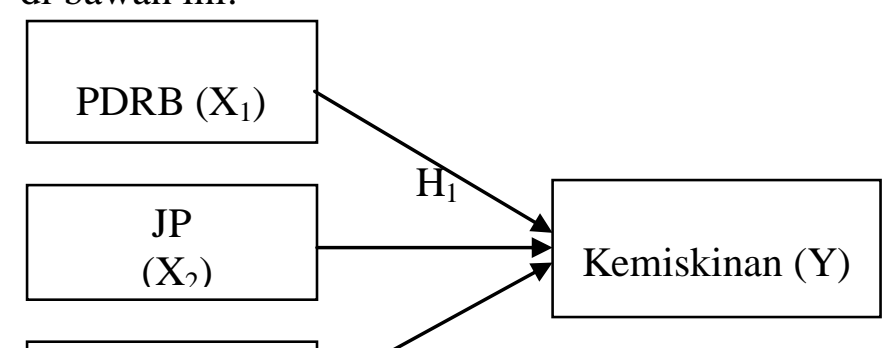

$\mathrm{H}_{2}$

$\mathrm{H}_{3}$

Sumber: Diolah (2019)

\section{Gambar 1 Kerangka Konseptual}

Berdasarkan Gambar 1 di atas, bahwa secara parsial variabel PDRB, jumlah penduduk dan IPM berpengaruh secara signifikan terhadap kemiskinan.

\section{Hipotesis}

$\mathrm{H}_{1}$ : Diduga PDRB berpengaruh secara signifikan terhadap kemiskinan pada Kab/Kota di Provinsi Aceh.

$\mathrm{H}_{2}$ : Diduga jumlah penduduk berpengaruh secara signifikan terhadap kemiskinan pada Kab/Kota di Provinsi Aceh.

$\mathrm{H}_{3}$ : Diduga indeks pembangunan manusia berpengaruh secara signifikan terhadap kemiskinan pada Kab/Kota di Provinsi Aceh.

\section{METODE PENELITIAN Data dan Sumber Data}

Jenis data yang digunakan dalam penelitian ini adalah data time series dan data cross section. Untuk data time series yang digunakan yakni dari tahun 2012-2018 (sebanyak 7 tahun) dan data cross section yaitu $23 \mathrm{Kab} / \mathrm{Kota}$, sehingga membentuk jumlah data panel yang akan diobservasi sebanyak 161 data. Sumber data dalam penelitian adalah berasal dari BPS Aceh, dimana data tersebut meliputi produk PDRB, jumlah penduduk, IPM serta kemiskinan di Kab/Kota Provinsi Aceh.

\section{Definisi Operasionalisasi Variabel}

1. Kemiskinan (Y). Yang dikatakan kemiskinan yaitu persentase penduduk miskin menurut Kab/Kota di Provinsi Aceh yang diperoleh dari BPS Aceh dan disajikan dalam satuan persen (\%).

2. PDRB $\left(\mathrm{X}_{1}\right)$. PDRB yang dimaksud adalah jumlah nilai tambah atau jumlah nilai barang dan jasa akhir yang dihasilkan unit usaha pada Kab/Kota di Provinsi Aceh. PDRB dalam penelitian ini yakni PDRB Migas atas dasar harga konstan $2010 \mathrm{Kab} /$ Kota se-Provinsi Aceh yang diperoleh dari BPS Aceh dan disajikan dalam satuan Juta Rupiah.

3. Jumlah penduduk $\left(\mathrm{X}_{2}\right)$. Jumlah penduduk yang dimaksud dalam penelitian ini adalah jumlah penduduk pada Kab/Kota di Provinsi Aceh yang 
diperoleh dari BPS Aceh dan disajikan dalam satuan jiwa.

4. IPM $\left(\mathrm{X}_{3}\right)$ adalah nilai indeks pembangunan manusia dari masing-masing Kab/Kota di Provinsi Aceh yang diperoleh dari BPS Aceh dan disajikan dalam satuan persen (\%).

\section{Metode Analisis Data}

Alat analisis yang digunakan dalam penelitian ini adalah model regresi data panel. Alat pengolahan data dalam penelitian ini dengan menggunakan program Eviews 9. Dalam model panel data, persamaan model dengan menggunakan data time series dan cross section. Untuk data time series yang digunakan yaitu dari tahun 2012-2018 (sebanyak 7 tahun) dan data cross section yaitu $23 \mathrm{Kab} / \mathrm{Kota}$, sehingga membentuk jumlah data panel yang akan diobservasi sebanyak 161 data. Adapun model $\log$ linier adalah sebagai berikut:

$K M K_{i t}=\beta_{0}+\beta_{1} \log +\beta_{2} \operatorname{LogJ} P_{i t}+\beta_{3} I P M_{i t}+\varepsilon_{i t}$

\section{Regresi Data Panel}

\section{Common Effect Model (PLS)}

Metode ini dikenal dengan estimasi common effect. Menurut Baltagi (2005), common effect model adalah model tanpa pengaruh individu penduga yang menggabungkan seluruh data time series dengan data cross section.

\section{Fixed Effect Model (FEM)}

Salah satu kesulitan prosedur panel data adalah bahwa asumsi intersep dan slope yang konsisten sulit terpenuhi. Menurut (Gujarati, D. N., \& Porter, 2012) model fixed effect menjelaskan perbedaan intersep antar individu koefisien (slope) dari variabel tetap sama antar individu atau sama antar waktu.

\section{Random Effect Model (REM)}

Apabila model fixeed effeect berdasarkan uji chow tidak terpenuhi, maka regresi data panel dilanjutkan dengan model random effeect. Model data panel yang didalamnya melibatkan korelasi antar error term karena berubahnya waktu dan berbedanya observasi dapat di atasi dengan pendekatan model random effect.

\section{HASIL DAN PEMBAHASAN Hasil Penelitian$$
\text { Hasil Uji Kesesuain Model Regresi Panel }
$$

Menurut Baltagi (2005), Gujarati (2012) dan Widarjono (2009) untuk menentukan model terbaik, dapat dilakukan dengan beberapa pengujian pemilihan model. Berikut adalah hasil uji chow pada penelitian ini:

Tabel 2

Hasil Uji Chow

Redundant Fixed Effects Tests

\begin{tabular}{lrrr} 
Effects Test & Statistic & d.f. & Prob. \\
\hline \hline Cross-section F & 85.987082 & $(22,135)$ & 0.0000 \\
Cross-section Chi-square & 436.132442 & 22 & 0.0000 \\
\hline \hline
\end{tabular}

Sumber: Hasil penelitian (2020)

Berdasarkan Tabel 2 di atas dapat dilihat bahwa hasil Uji Chow (Redundant Fixed Effects Tests memiliki nilai probabilitas sebesar 0,0000 < alpha 0,05 ), sehingga $\mathrm{H}_{0}$ ditolak dan $\mathrm{H}_{1}$ diterima, model yang sesuai untuk penelitian ini adalah model fixed effect (Hal tersebut ditandai dengan nilai probabilitas $\mathrm{F}$ sebesar $0,0000<0,05$ ), maka bisa dilanjutkan untuk melihat Model Random Effect.

Sedangkan Uji Hausman menguji apakah data tersebut dianalisis dengan menggunakan fixed effect atau random effect. Hipotesis dalam uji Hausman adalah: $\mathrm{H}_{0}$ : Random effect model sementara $\mathrm{H}_{1}$ : Fixed effect model. Berikut adalah hasil uji Hausman pada penelitian ini:

Tabel 3

Hasil Uji Hausman

Correlated Random Effects - Hausman Test

\begin{tabular}{lrrr}
\hline \hline & $\begin{array}{c}\text { Chi-Sq. } \\
\text { Statistic }\end{array}$ & Chi-Sq. d.f. & Prob. \\
\hline \hline Cross-section random & 2.741890 & 3 & 0.4332 \\
\hline \hline
\end{tabular}

Sumber: Hasil penelitian (2020)

Berdasarkan Tabel 3, diperoleh nilai Prob. ( $p$-value) yang didapat adalah sebesar 0.4332. Nilainya lebih besar dari taraf signifikansi 0,05 atau $5 \%(0.4332>0,05)$, maka terima $\mathrm{H}_{0}$ dan tolak $\mathrm{H}_{1}$ yang berarti bahwa tolak model fixed effect dan menerima model Random Effect. Oleh karena itu dapat disimpulkan bahwasannya berdasarkan $U j i$ Hausman model yang terbaik digunakan untuk penelitian ini adalah Random effect model, karena 
model yang terpilih adalah REM, maka uji asumsi klasik tidak perlu dilakukan (Gujarati, D. N., \& Porter, 2012).

\section{Hasil Regresi Data Panel}

Adapun hasil estimasi random effect model untuk penelitian ini adalah sebagai berikut:

\section{Tabel 4}

\section{Hasil Estimasi REM}

Dependent Variable: KMK?

\begin{tabular}{lrrrr}
\hline \hline \multicolumn{1}{c}{ Variable } & Coefficient & Std. Error & t-Statistic & Prob. \\
\hline \hline C & 70.22248 & 9.310899 & 7.541966 & 0.0000 \\
LOGPDRB? & -1.140155 & 0.748119 & -1.524028 & 0.1295 \\
LOGJP? & -0.370361 & 0.234196 & -1.581417 & 0.1158 \\
$\quad$ IPM? & -0.452591 & 0.067848 & -6.670631 & 0.0000 \\
\hline \hline R-squared & & 0.385760 & \\
Adjusted R-squared & & 0.374023 & \\
F-statistic & & 32.86683 & \\
Prob(F-statistic) & & 0.000000 & \\
Durbin-Watson stat & & 0.861331 & \\
\hline \hline
\end{tabular}

Sumber: Hasil penelitian (2020)

$K M K_{i t}=70.22-1.14$ LnPDRB $_{i t}-0.37 L n J P_{i t}-0.45 I P M_{i t}$

Nilai konstanta/intersep pada Kabupaten Aceh Barat adalah sebesar 74,65. Apabila PDRB, jumlah penduduk dan IPM dianggap konstan (tetap) maka kemiskinan juga akan konstan sebesar 74,65. Nilai konstanta/intersep pada Kabupaten Aceh Barat Daya adalah sebesar 68,29. Apabila PDRB, jumlah penduduk dan IPM dianggap konstan (tetap) maka kemiskinan juga akan konstan sebesar 68,29.

Nilai konstanta/intersep pada Kabupaten Aceh Besar adalah sebesar 71,26. Apabila PDRB, jumlah penduduk dan IPM dianggap konstan (tetap) maka kemiskinan juga akan konstan sebesar 71,26. Nilai konstanta/intersep pada Kabupaten Aceh Jaya adalah sebesar 67,22. Apabila PDRB, jumlah penduduk dan IPM dianggap konstan (tetap) maka kemiskinan juga akan konstan sebesar 67,22.

Nilai konstanta/intersep pada Kabupaten Aceh Selatan adalah sebesar 64,15. Apabila PDRB, jumlah penduduk dan IPM dianggap konstan (tetap) maka kemiskinan juga akan konstan sebesar 64,15. Nilai konstanta/intersep pada Kabupaten Aceh Singkil adalah sebesar 69,85. Apabila PDRB, jumlah penduduk dan IPM dianggap konstan (tetap) maka kemiskinan juga akan konstan sebesar 69,85.

Nilai konstanta/intersep pada Kabupaten Aceh Tamiang adalah sebesar 67,32. Apabila PDRB, jumlah penduduk dan IPM dianggap konstan (tetap) maka kemiskinan juga akan konstan sebesar 67,32. Nilai konstanta/intersep pada Kabupaten Aceh Tengah adalah sebesar 71,56. Apabila PDRB, jumlah penduduk dan IPM dianggap konstan (tetap) maka kemiskinan juga akan konstan sebesar 71,56.

Nilai konstanta/intersep pada Kabupaten Aceh Tenggara adalah sebesar 66,25. Apabila PDRB, jumlah penduduk dan IPM dianggap konstan (tetap) maka kemiskinan juga akan konstan sebesar 66,25. Nilai konstanta/intersep pada Kabupaten Aceh Timur adalah sebesar 67,90. Apabila PDRB, jumlah penduduk dan IPM dianggap konstan (tetap) maka kemiskinan juga akan konstan sebesar 67,90.

Nilai konstanta/intersep pada Kabupaten Aceh Utara adalah sebesar 73,75. Apabila PDRB, jumlah penduduk dan IPM dianggap konstan (tetap) maka kemiskinan juga akan konstan sebesar 73,75. Nilai konstanta/intersep pada Kota Banda Aceh adalah sebesar 68,57. Apabila PDRB, jumlah penduduk dan IPM dianggap konstan (tetap) maka kemiskinan juga akan konstan sebesar 68,57.

Nilai konstanta/intersep pada Kabupaten Bener Meriah adalah sebesar 75,45. Apabila PDRB, jumlah penduduk dan IPM dianggap konstan (tetap) maka kemiskinan juga akan konstan sebesar 75,45. Nilai konstanta/intersep pada Kabupaten Bireun adalah sebesar 71,03. Apabila PDRB, jumlah penduduk dan IPM dianggap konstan (tetap) maka kemiskinan juga akan konstan sebesar 71,03.

Nilai konstanta/intersep pada Kabupaten Gayo Lues adalah sebesar 71,34. Apabila PDRB, jumlah penduduk dan IPM dianggap konstan (tetap) maka kemiskinan juga akan konstan sebesar 71,34. Nilai konstanta/intersep pada Kota Langsa adalah sebesar 67,26. Apabila PDRB, jumlah penduduk dan IPM dianggap konstan (tetap) maka kemiskinan juga akan konstan sebesar 67,26.

Nilai konstanta/intersep pada Kota Lhokseumawe adalah sebesar 68,81. Apabila PDRB, jumlah penduduk dan IPM dianggap konstan (tetap) maka kemiskinan juga akan konstan sebesar 68,81. Nilai konstanta/intersep pada Kabupaten Nagan Raya adalah sebesar 72,56. Apabila PDRB, jumlah penduduk dan IPM dianggap konstan (tetap) maka kemiskinan juga akan konstan sebesar 72,56.

Nilai konstanta/intersep pada Kabupaten Pidie adalah sebesar 74,80. Apabila PDRB, jumlah 
penduduk dan IPM dianggap konstan (tetap) maka kemiskinan juga akan konstan sebesar 74,80. Nilai konstanta/intersep pada Kabupaten Pidie Jaya adalah sebesar 74,82. Apabila PDRB, jumlah penduduk dan IPM dianggap konstan (tetap) maka kemiskinan juga akan konstan sebesar 74,82.

Nilai konstanta/intersep pada Kota Sabang adalah sebesar 70,20. Apabila PDRB, jumlah penduduk dan IPM dianggap konstan (tetap) maka kemiskinan juga akan konstan sebesar 70,20. Nilai konstanta/intersep pada Kota Simeulue adalah sebesar 69,23. Apabila PDRB, jumlah penduduk dan IPM dianggap konstan (tetap) maka kemiskinan juga akan konstan sebesar 69,23. Nilai konstanta/intersep pada Kota Subulussalam adalah sebesar 68,06. Apabila PDRB, jumlah penduduk dan IPM dianggap konstan (tetap) maka kemiskinan juga akan konstan sebesar 68,06.

Nilai koefisien regresi variabel PDRB adalah sebesar -1.14, artinya jika PDRB meningkat 1 persen, maka kemiskinan pada Kab/Kota di Provinsi Aceh akan menurun sebesar 1.14 persen dengan asumsi bahwa variabel jumlah penduduk dan indeks pembangunan manusia dianggap konstan,.

Nilai koefisien regresi variabel jumlah penduduk adalah sebesar -0.37, artinya jika jumlah penduduk meningkat 1 persen, maka kemiskinan pada Kab/Kota di Provinsi Aceh akan menurun sebesar 0.37 persen dengan asumsi bahwa variabel PDRB dan indeks pembangunan manusia dianggap konstan.

Nilai koefisien regresi variabel IPM adalah sebesar -0.45 , artinya jika IPM meningkat 1 point, maka kemiskinan pada Kab/Kota di Provinsi Aceh akan menurun sebesar 0.45 persen dengan asumsi bahwa variabel PDRB dan jumlah penduduk dianggap konstan.

\section{Pengujian Hipotesis \\ Hasil Uji t}

Berdasarkan hasil estimasi yang ditunjukkan pada Tabel 4, dapat dilihat bahwa: PDRB memiliki $t_{\text {hitung }}$ sebesar -1.524 dengan nilai probabilitas statistiknya sebesar 0.1295 , dan dengan nilai $\mathrm{t}_{\text {tabel }}$ yaitu $(\mathrm{df})=\mathrm{n}-\mathrm{k}=(161-4=157)$ pada $\alpha=10 \%(0,10)$ diperoleh nilai 1.655 , oleh karena $1.524<1.655$. Hal ini juga bisa dilihat dari nilai probabilitas ( $P$-value $)$ sebesar $0.1295>$ 0,10 , maka dapat disimpulkan bahwa $\mathrm{t}_{\text {hitung }}\left\langle\mathrm{t}_{\text {tabel }}\right.$ yaitu $1.524<1.655(-1.524>-1.655)$, maka tolak $\mathrm{H}_{1}$ dan terima $\mathrm{H}_{0}$, yang berarti bahwa variabel PDRB tidak berpengaruh secara signifikan terhadap kemiskinan pada Kab/Kota di Provinsi Aceh.

Jumlah penduduk memiliki $t_{\text {hitung }}$ sebesar 1.581 dengan nilai probabilitas statistiknya sebesar 0.1158 , dan dengan nilai $\mathrm{t}_{\text {tabel }}$ yaitu $(\mathrm{df})=\mathrm{n}-\mathrm{k}=$ $(161-4=157)$ pada $\alpha=10 \%(0,10)$ diperoleh nilai 1.655. Hal ini juga bisa dilihat dari nilai probabilitas ( $P$-value) sebesar $0.1158>0,10$, maka dapat disimpulkan bahwa $\mathrm{t}_{\text {hitung }}<\mathrm{t}_{\text {tabel }}$ yaitu 1.581 $<1.655(-1.581>-1.655)$, maka tolak $\mathrm{H}_{2}$ dan terima $\mathrm{H}_{0}$, yang berarti bahwa variabel jumlah penduduk tidak berpengaruh secara signifikan terhadap kemiskinan pada Kab/Kota di Provinsi Aceh.

IPM memiliki $t_{\text {hitung }}$ sebesar -6.671 dengan nilai probabilitas statistiknya sebesar 0.0000 , dan dengan nilai $\mathrm{t}_{\text {tabel }}$ yaitu $(\mathrm{df})=\mathrm{n}-\mathrm{k}=(161-4=157)$ pada $\alpha=1 \%(0,01)$ diperoleh nilai 2.608 . Hal ini juga bisa dilihat dari nilai probabilitas ( $P$-value $)$ sebesar $0.0000<0,01$, maka dapat disimpulkan bahwa $t_{\text {hitung }}>\mathrm{t}_{\text {tabel }}$ yaitu $6.671>2.608(-6.671<-$ 2.608), maka tolak $\mathrm{H}_{0}$ dan terima $\mathrm{H}_{3}$, yang berarti bahwa variabel IPM berpengaruh secara signifikan dan negatif terhadap kemiskinan pada Kab/Kota di Provinsi Aceh.

\section{Hasil Uji F}

Uji Berdasarkan hasil estimasi yang terdapat pada Tabel 4, maka dapat dilihat bahwa nilai $F_{\text {hitung }}$ sebesar 32.867 dan nilai signifikansi sebesar 0.000 pada taraf kepercayaan $1 \%$. Sedangkan $F_{\text {tabel }}$ df1= $\mathrm{k}-1=(4-1=3)$ dan df $2=\mathrm{n}-\mathrm{k}=(161-4=157)$ diperoleh nilai sebesar 3.91 pada $\alpha=0.01$, maka $\mathrm{F}_{\text {hit }}>\mathrm{F}_{\text {tab }}$ yaitu $32.87>3.91$, maka tolak $\mathrm{H}_{0}$ dan terima $\mathrm{H}_{\mathrm{a}}$, yang berarti bahwa secara bersama-sama variabel PDRB, jumlah penduduk dan indeks pembangunan manusia berpengaruh secara signifikan dan positif terhadap kemiskinan pada Kab/Kota di Provinsi Aceh. Hal ini juga bisa dilihat dari probabilitas $(P$-value $)$ sebesar $0.000<0,01$.

\section{Koefisien Determinasi $\left(\mathbf{R}^{2}\right)$ dan Koefisien Korelasi (R) \\ Koefisien Determinasi $\left(\mathbf{R}^{2}\right)$}

Dilihat dari nilai Adjusted R-squared $=0.374$, maka dapat disimpulkan bahwa besarnya pengaruh PDRB, jumlah penduduk dan IPM terhadap kemiskinan pada Kab/Kota di Provinsi Aceh adalah

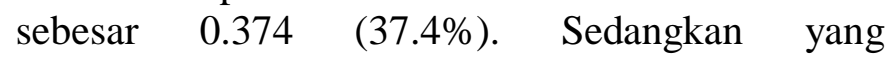
dipengaruhi oleh variabel lain diluar penelitian ini adalah sebesar $0,626(62.6 \%)$.

\section{Koefisien Korelasi (R)}

Hasil koefisien korelasi diperoleh $\mathrm{R}=$ $\sqrt{0.3858}=0.6211$. Jadi hubungan antara variabel PDRB, jumlah penduduk dan IPM terhadap 
kemiskinan pada Kab/Kota di Provinsi Aceh berhubungan kuat secara positif karena nilai korelasi mendekati angka positif 1 .

\section{Hasil Pembahasan}

\section{Pengaruh PDRB Terhadap Kemiskinan Di Provinsi Aceh}

Hasil yang diperoleh dari penelitian ini menunjukkan bahwa variabel PDRB tidak berpengaruh terhadap kemiskinan pada Kab/Kota di Provinsi Aceh. Hasil penelitian ini sejalan dengan penelitian terdahulu yang dilakukan oleh (Alhudori, 2017) dimana PDRB tidak terhadap penduduk miskin di Pulau Jambi. Namun, hasil penelitian ini berbeda dengan hasil penelitian yang dilakukan oleh (Giovanni, 2018) dimana PDRB berpengaruh tehadap kemiskinan di Pulau Jawa.

Hasil penelitian ini berbanding terbalik
dengan teori yang menyatakan bahwa pertumbuhan PDRB yang tinggi dan berkelanjutan merupakan kondisi utama atau suatu keharusan bagi kelangsungan pembangunan ekonomi dalam hal peningkatan kesejahteraan. Namun pada kenyataanya pertumbuhan ekonomi di Kab/Kota pada Provinsi Aceh tidak dibarengi dengan pemerataan.

Ini menandakan bahwa meskipun PDRB terus mengalami peningkatan setiap tahunnya namun kesempatan kerja yang tersedia justru tidaklah merata sehingga mengakibatkan adanya ketimpangan dalam pembagian penambahan pendapatan (cateris paribus), ada penduduk yang mendapatkan pendapatan di atas rata-rata, dan ada pula penduduk yang memiliki pendapatan di bawah rata-rata. Dengan adanya ketidakmerataan, kesejahteraan yang diperoleh penduduk di Provinsi Aceh semakin berkurang. Oleh karena itu, tingginya PDRB suatu daerah tidak menjamin bahwa daerah tersebut telah memiliki kesejahteraan yang tinggi dengan tingkat kemiskinan yang rendah.

Contoh kasus pada penelitian ini yakni pada tahun 2018, Kabupaten Aceh Utara mempunyai PDRB tertinggi diantara total $23 \mathrm{Kab} /$ Kota yang ada di Provinsi Aceh. Seharusnya dengan peningkatan tersebut mampu menjadikan Aceh Utara sebagai kabupaten dengan tingkat kemiskinan yang paling rendah. Namun pada kenyataan yang terjadi justru sebaliknya, Aceh Utara berada di urutan ke-14 dengan presentase jumlah penduduk terbanyak dari total 23 Kab/Kota yang ada di Provinsi Aceh.

Berdasarkan kondisi tersebut, maka membuktikan bahwa peningkatan pertumbuhan ekonomi di Provinsi Aceh tidak dibarengi dengan pemerataan. Dimana, masih terdapat kesenjangan/ketimpangan antara yang memiliki PDRB yang paling tinggi, justru memiliki jumlah penduduk miskin yang lebih banyak daripada yang sudah jelas memiliki nilai PDRB yang lebih rendah. Hal ini menunjukkan bahwa tinggi atau rendahnya PDRB tidak berpengaruh terhadap kemiskinan.

\section{Pengaruh Jumlah Penduduk Terhadap Kemiskinan Di Provinsi Aceh}

Hasil penelitian membuktikan bawa jumlah penduduk kemiskinan pada Kab/Kota di Provinsi Aceh. Hasil penelitian ini serupa dengan penelitian terdahulu yang dlakukan oleh (Pattimahu, 2016) dan (Fadlillah \& Dkk, 2016) dimana jumlah penduduk tidak berpengaruh terhadap tingkat kemiskinan. Namun penelitian ini tidak sejalan dengan penelitian (Silastri, 2017) yang mana jumlah penduduk berpengaruh terhadap kemiskinan.

Ada beberapa hal yang menjadikan penduduk sebagai pemicu pembangunan dan berpengaruh negatif terhadap tingkat kemiskinan. Jumlah penduduk akan menjadi masalah bagi pemerintah jika tidak bisa dikendalikan, karena jika jumlah penduduk tiap tahun makin bertambah maka akan menyebabkan angka kemiskinan juga tinggi. Pertumbuhan penduduk bisa mengurangi angka kemiskinan tergantung dari masyarakat mendapatkan pekerjaan yang bisa memenuhi kebutuhannya.

Pertumbuhan penduduk bisa mengurangi angka kemiskinan. Akan tetapi contoh kasus dalam penelitian ini adalah sebaliknya, diimana pda tahun 2018 Aceh Utara menjadi Kabupaten yang memiliki jumlah penduduk terbanyak di Provinsi Aceh. Seharusnya posisi tersebut mampu menjadikan Aceh Utara sebagai Kabupaten dengan tingkat kemiskinan yang paling rendah. Namun fenomenanya justru menunjukkan bahwa Aceh Utara adalah Kabupaten dengan nomor urut ke-14 dengan jumlah penduiduk miskin terbanyak di Provinsi Aceh.

Hasil penelitian ini membuktikan bahwa tinggi atau rendahnya pertumbuhan jumlah penduduk suatu daerah belum tentu menjamin bahwa daerah tersebut memiliki angka kemiskinan yang rendah. Pertumbuhan jumlah penduduk dalam penelitian ini tidak berpengaruh terhadap kemiskinan karena pada kenyataanya peningkatan jumlah penduduk di Provinsi Aceh tidak diikuti dengan peningkatan lapangan kerja yang tersedia, yang mampu menurunkan angka kemiskinan. 
Dengan pertumbuhan penduduk yang semakin tinggi maka lapangan kerja yang dibutuhkan juga akan semakin banyak. Akan tetapi fenomenanya, jumlah pencari kerja justru lebih banyak daripada jumlah lapangan usaha yang tersedia. Artinya, masih ada penduduk yang belum mendapatkan pekerjaan sehingga pada akhirnya menjadi pengangguran. Tanpa adanya pendapatan, maka seseorang tidak akan mampu memenuhi kebutuhan, ini berdampak pada menurunnyajumlah konsumsi.

Apabila konsumsi secara agregat mengalami penurunan maka PDRB juga akan mengalami penurunan karena pehitungan PDRB salah satunya dihitung dari konsumsi masyarakat secara agregat. Sehingga menurunnya PDRB akan menurunkan pendapatan per kapita yang mengakibatkan kesejahteraan masyarakat menjadi menurun. Mengingat bahwa kesejahteraan memilikihubungan yang negatif terhadap kemiskinan, maka menurunnya kesejahteraan masyarakat akan berdampak pada meningkatnya kemiskinan.

\section{Pengaruh Indeks Pembangunan Manusia Terhadap Kemiskinan Di Provinsi Aceh}

Hasil penelitian ini sejalan dengan penelitian terdahulu yang dilakukan oleh (Fadlillah \& Dkk, 2016) dan (Alhudori, 2017) dimana indeks pembangunan manusia berpengaruh terhadap kemiskinan. Akan tetapi, hasil penelitian ini bebeda dengan hasil penelitian yang dlakukan oleh (Syaifullah \& Nazaruddin, 2017) dimana IPM tidak berpengruh secara signifikan terhadap kemiskinan.

Indeks Pembangunan Manusia (IPM) merupakan suatu terobosan dalam menilai pembangunan manusia. Kualitas hidup manusia yang semakin baik akan menjadi penunjang faktor berkurangnya penduduk miskin. Pada hakikatnya pembangunan merupakan pembangunan manusia. Menurut (Adi \& Christy, 2009) memprioritaskan belanja dalam peningkatan pembangunan SDM akan mampu meningkatkan kesejahteraan masyarakat. Upaya yang dilakukan antara lain memperluas peluang penduduk agar tercapai kehidupan yang layak, melalui peningkatan produktivitas, ilmu pengetahuan serta derajat kesehatan. Kualitas hidup manusia yang semakin baik akan menjadi penunjang faktor berkurangnya penduduk miskin.

Hasil penelitian ini menunjukkan bahwa indeks pembangunan manusia berpengaruh secara negatif dan signifikan terhadap kemiskinan pada Kab/Kota di Provinsi Aceh. Hal ini berarti bahwa jika IPM meningkat maka kemiskinan akan menurun. Begitu pula sebaliknya, jika IPM menurun maka akan meningkatkan kemiskinan. Jika IPM meningkat maka menunjukkan bahwasannya kualitas hidup seseorang semakin berkualitas sehingga kesejahteraan semakin tinggi dan tingkat kemiskinan akan berkurang.

Dari 23 kabupaten/kota yang terdapat di Provinsi Aceh memiliki keberagaman baik dari segi potensi sumber daya alam maupun sumber daya manusia. Hal ini menyebabkan capaian pembangunan manusia berbeda pada setiap daerah. Faktor-faktor penentu keberhasilan capaian pembangunan ditentukan dari program-program pembangunan yang diselenggarakan oleh pemerintah daerah. Disamping upaya pengawasan dan evaluasi terhadap program-program pembangunan untuk mempercepat peningkatan pembangunan manusia.

Secara umum, kualitas manusia di masingmasing kabupaten/kota di Aceh yang diukur melalui IPM terlihat menunjukkan tren peningkatan dari tahun ke tahun, sama halnya dengan agregat IPM Aceh. Daerah-daerah dengan IPM yang relatif tinggi mampu mempertahankan prestasinya (meskipun ada yang naik-turun peringkatnya), sementara daerah yang masih lebih rendah semakin terpacu untuk meningkatkan kapabilitas manusia di masing-masing komponen pembentuknya.

\section{PENUTUP}

\section{Kesimpulan}

Berdasarkan hasil penelitian dan pembahasan di atas, maka penulis dapat mengambil beberapa kesimpulan diantaranya adalah sebagai berikut:

1. PDRB tidak berpengaruh secara signifikan terhadap kemiskinan pada Kab/Kota di Provinsi Aceh. Hasil ini menunjukkan bahwa meningkatnya PDRB tidak mampu menurunkan kemiskinan.

2. Jumlah penduduk tidak berpengaruh secara signifikan terhadap kemiskinan pada Kab/Kota di Provinsi Aceh.

3. Indeks pembangunan manusia berpengaruh secara signifikan dan negatif terhadap kemiskinan pada Kab/Kota di Provinsi Aceh. Hasil ini menunjukkan bahwa meningkatnya IPM dapat menurunkan kemiskinan.

\section{Saran}

Berdasarkan uraian yang telah disampaikan pada bab sebelumnya, maka saran yang dapat 
diberikan dari hasil penelitian ini adalah sebagai berikut:

1. Diharapkan agar pemerintah Kabupaten/Kota, dapat meningkatkan IPM Kabupaten/Kota, agar dapat mensejahterakan rakyat dan menurunkan tingkat kemiskinan. Hal ini karena IPM merupakan suatu ukuran yang digunakan untuk mengukur pencapaian pembangunan manusia di suatu wilayah. Meskipun tidak mengukur semua dimensi dari pembangunan manusia, namun IPM dinilai mampu mengukur dimensi pokok dari pembangunan manusia.

2. Diharapkan agar pemerintah mampu meningkatkan tingkat pendidikan di Provinsi Aceh. Hal ini dikarenakan, salah satu hambatan peningkatan kapasitas dasar penduduk adalah tingginya biaya pendidikan. Ketidakmampuan untuk membiayai sekolah akan berdampak pada pilihan untuk tidak melanjutkan pendidikan ke jenjang yang lebih tinggi atau tidak menamatkan jenjang pendidikan yang sedang dijalani. Menyikapi hal ini, pemerintah telah membebaskan biaya pendidikan serta pemberian beasiswa bagi siswa berprestasi. Namun, manfaat dari program tersebut belum sepenuhnya dapat dinikmati secara luas oleh masyarakat, sehingga angka putus sekolah cukup tinggi pada kelompok umur 16-18 tahun di Provinsi Aceh.

3. Selanjutnya diharapkan semakin sempit perbedaan/disparitas pertumbuhan IPM maka semakin merata kecepatan pembangunan manusia menuju ideal antarkabupaten/kota di Provinsi Aceh.

\section{DAFTAR PUSTAKA}

Adi, P. ., \& Christy, F. (2009). Hubungan Antara Dana Alokasi Umum, Belanja Modal dan Kualitas Pembangunan Manusia. The $3 r d$ National Conference UKWMS. Surabaya.

Alhudori, M. (2017). Pengaruh IPM, PDRB, dan Jumlah Pengangguran Terhadap Penduduk Miskin di Provinsi Jambi. Jurnal of Economics and Business, Vol: 1(1).

Andriyani, D., \& Juliansyah, H. (2018). Analisis Disparitas Wilayah di Provinsi Aceh : Telaah pada. Jurnal Ekonomi Regional Unimal, 01(2003), 30-37.

Arsyad, L. (2004). Ekonomi Pembangunan. Edisi Keempat. STIE YKPN.
BPS. (2019). Persentase Penduduk Miskin Menurut Kabupaten/Kota, 2015-2018.

BPS Provinsi Aceh. (2019). Provinsi Aceh Dalam Angka 2019. Katalog BPS.

Davies, A. (2018). A Panel Data Analysis of the Impact of Trade on Human Development A Panel Data Analysis of the Impact of Trade on Human Development. January. https://doi.org/10.1016/j.socec.2005.11.048

Fadlillah, N., \& Dkk. (2016). Analisis Pengaruh Pendapatan Per Kapita, Tingkat Pengangguran, IPM dan Pertumbuhan Penduduk Terhadap Kemiskinan di Jawa Tengah Tahun 2009-2013. Eko-Regional, Vol: 11(1).

Franciari \& Sugiyanto. (2013). Analisis Hubungan IPM, Kapasitas Fiskal dan Korupsi Terhadap Kemiskinan Di Indonesia (Studi Kasus 38 Kabupaten/kota Di Indonesia Tahun 2008). Diponegoro Journal Of Economics, Vol: 2(2).

Giovanni, R. (2018). Analisis Pengaruh PDRB, Pengangguran dan Pendidikan Terhadap Tingkat Kemiskinan di Pulau Jawa Tahun 2009-2016. Economics Development Analysis Journalcs Development Analysis Journal, Vol: 7(1).

Gujarati, D. N., \& Porter, D. C. (2012). DasarDasar Ekonometrika. Edisi Lima. Selemba Empat.

Hardinandar, F. (2019). Determinan Kemiskinan (Studi Kasus 29 Kota/Kabupaten Di Provinsi Papua). Jurnal REP (Riset Ekonomi Pembangunan).

Pattimahu, T. V. (2016). Analisis Pengaruh Jumlah Penduduk dan Pengangguran Terhadap Tingkat Kemiskinan Di Maluku. Cita Ekonomika, Jurnal Ekonomi, Vol: 10(1).

Ritonga, H. (2003). Perhitungan Penduduk Miskin. Badan Pusat Statistik.

Silastri, N. (2017). Pengaruh Jumlah Penduduk dan Pendapatan Domestik Regional Bruto (PDRB) Terhadap Kemiskinan di Kabupaten Kuantan Singingi. JOM Fekon, Vol: 4(1), 105-117.

Sukirno, S. (2005). Mikro Ekonomi, Teori Pengantar. PT Raja Grafindo Persada.

Suparlan, P. (2004). Kemiskinan di Perkotaan. Yayasan Obor Indonesia.

Syaifullah, A., \& Nazaruddin, M. (2017). PENGARUH INDEKS PEMBANGUNAN MANUSIA DAN PRODUK DOMESTIK 
BRUTO TERHADAP TINGKAT

KEMISKINAN DI ASEAN-4 (Studi Pada 4

Negara ASEAN). 1, 107-119.

Thamrin, S. (2001). Analisis Potensi Pendapatan

Asli Daerah, Bunga Rampai Manajemen

Keuangan Daerah. UPP AMPM YKPN.

Todaro. (2006). Pembangunan Ekonomi Edisi keDELAPAN. Erlangga.

Widodo, T. (2009). Perencanaan Pembangunan: Aplikasi Komputer. STIE YKPN.

Wongdesmiwati. (2009). Pertumbuhan Ekonomi dan Pengentasan Kemiskinan Di Indonesia: Analisis Ekonometrika.

https://doi.org/http://wongdesmiwati.files.w ordpress.com/2009/10 